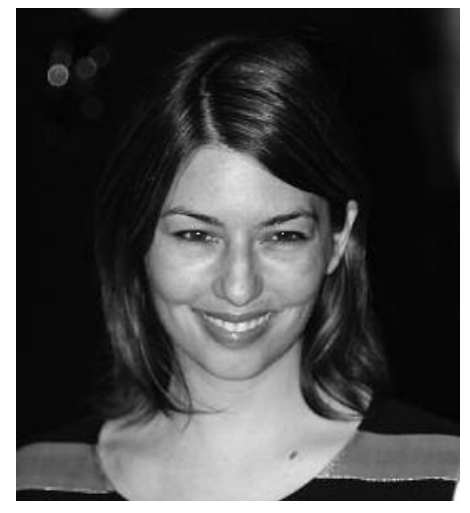

Sofia Coppola nació el 14 de mayo de 1971, en Nueva York.

Es directora, guionista, productora y actriz. Incluso se puede ver su nombre asociado al diseño de vestuario de algunos trabajos.

Ha trabajado como actriz en cine y televisión. Algunas de las películas donde podemos verla son: Star Wars: Episodio I - La amenaza fantasma, El Padrino, tercera parte, Peggy Sue se casó.

También ha sido productora de cine y televisión. De hecho, ha producido sus dos últimas películas, María Antonieta y Lost in traslation.

Como productora ejecutiva podemos verla en la serie Platinum y High Octane, entre otras.

Como guionista, ha escrito sus tres largometrajes, María Antonieta, Lost in traslation y Las vírgenes suicidas, además del episodio de Historias de Nueva York, dirigido por su padre. 


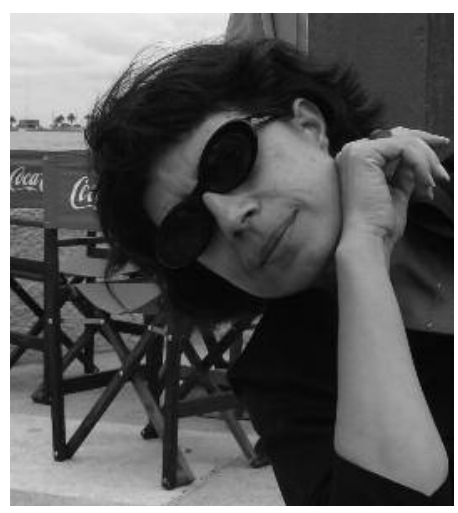

Yolanda García SeRRAno. Tras el bachiller, estudió Relaciones Públicas y trabajó durante varios años en una oficina ejerciendo como secretaria. Mientras, estudiaba arte dramático y enseguida empezó a escribir teatro, primero infantil y luego para adultos. Ha realizado varios cursos y talleres de escritura dramática con Fermín Cabal, Jose Luis Alonso de Santos, Jesús Campos... También narrativa, relato, etc., y aún hoy en día sigue aprendiendo en distintos talleres.

Estudió guión con Joaquín Oristrell, Lola Salvador y Manolo Matgi, y ha hecho talleres con guionistas norteamericanos e hispanos. Su carrera como guionista profesional comenzó en 1988, y desde entonces ha realizado guiones para películas, cortos, programas y series de televisión y de radio.

Ha dirigido algunas películas y series de televisión, como Hasta aquí hemos llegado (cine), Raquel busca su sitio (serie TVE) o La verdad después de la sonrisa (teatro), y es asimismo autora de teatro, directora y productora, y autora de novela. Es profesora de guión ECAM y de teatro. Imparte clases a niños de preescolar.

Entre los premios recibidos se encuentran el Goya al mejor guión original por Todos los hombres sois iguales, el Premio a la mejor película de L.A. Gay \& Lesbian Film Festival a Amor de hombre, y el Premio a la mejor película en el Festival de Turín a Km 0 .

$\Rightarrow$ yolandezster@gmail.com 


\title{
SOFIA ENTRE MUJERES
}

YolANDA García SERRANO

\begin{abstract}
RESUMEN
Sofia Coppola ha tenido que luchar para lograr un reconocimiento propio como guionista y directora. Con tan sólo tres largometrajes en su haber, ha demostrado al público y a la crítica que su talento es independiente de su apellido. El aislamiento, la juventud, los hijos o el erotismo son temas coincidentes en las tres películas, donde la mujer brilla por encima de todo. Sus protagonistas nos hablan de las preocupaciones inherentes a su edad: qué hacer con el futuro, lo difícil que es amar, las primeras relaciones, el sexo, las relaciones materno-filiales, el miedo. En una palabra: la vida. Y de todo ello nos habla con personalidad propia y un punto de vista original, lo más difícil de encontrar en esta profesión.

$\Rightarrow$ PALABRAS ClAVE: aislamiento, juventud, hijos, erotismo.
\end{abstract}

\section{«CUANTO MÁS SABES LO QUE QUIERES Y LO QUE ERES, MENOS TE INCOMODAN LAS COSAS»}

Esta frase, escrita por Sofia Coppola para el guión de su película Lost in translation, podría muy bien ser una declaración pública de sus sentimientos. Con tan sólo treinta y ocho años, Coppola tiene una trayectoria sobre la que se han escrito infinidad de artículos, lo que es lógico teniendo en cuenta que nació con uno de los apellidos más importantes de la industria cinematográfica internacional. Pero ateniéndonos únicamente a su faceta de guionista, podríamos tratar de descubrir qué inquietudes se esconden tras esta mujer que nació en el seno de una familia artística de éxito. Si un guionista elige los temas sobre los que va a escribir, esos mismos temas marcan la trayectoria del autor y definen la personalidad del mismo por encima de sus pretensiones. 
Guionista y directora de tres largometrajes, Las vírgenes suicidas, Lost in translation y María Antonieta, Sofia parece abordar un tema principal a la hora de realizar sus proyectos: el aislamiento. Pero hay otros temas coincidentes en las tres historias que iremos viendo paso a paso. Para desarrollar este razonamiento, habrá que analizar sus películas y ver en qué puntos coinciden y cómo he llegado a esta conclusión.

\section{EL AISLAMIENTO}

Por encima de todos los demás temas, el aislamiento tiñe las tres historias sobre las que la guionista/directora ha decidido escribir en su carrera cinematográfica. Que sea premeditado o no, sólo ella lo sabe, pero sin duda los guiones hablan más de sus autores que los autores mismos.

1. En la primera película, Las vírgenes suicidas, con guión basado en la novela de Jeffrey Eugenides, muestra a cinco hermanas entre los trece y los diecisiete años marcadas por una madre rígida y religiosa que, tras el suicidio de la más pequeña, siente un miedo atroz a lo que les pueda pasar al resto de sus hijas. Pero ese miedo, sobre todo relacionado con el sexo, ya estaba presente antes del suicidio y centrado en la figura de la segunda hija, Lux, de tan sólo catorce años. Un detalle que lo confirma: cuando invitan a un joven a cenar, ella es a la única a la que obliga a ponerse una rebeca para tapar sus hombros apenas desnudos. De la opinión del padre no sabemos prácticamente nada, excepto que vive en su mundo y nunca le lleva la contraria a su mujer, aunque está de parte de sus hijas en la medida de lo posible. 
Un tiempo después, Lux, convertida en la más pequeña tras el suicidio de su hermana, se ausenta de casa durante toda una noche y eso provoca que la madre decida encerrarlas a todas sin posibilidad de salir, ni siquiera de asistir a clase.

A partir de este momento, el aislamiento físico es el eje central de la película. Las hermanas viven sin contacto con el exterior, a excepción de lo que atisban desde la ventana. En realidad, el grupo de hermanas funciona como un personaje único desde el encierro hasta el desenlace final. Ni ellas pueden salir, ni las pueden visitar. La casa, como símbolo de la familia, convertida en cárcel. Se relacionan con los vecinos a escondidas a través de la música escuchada por teléfono, Lux mantiene relaciones sexuales en el tejado con cualquier desconocido que se preste, las hermanas imaginan planes de futuro expresados a través de folletos de viaje, pero en sus cabezas se va forjando la idea que las conducirá al fatal suicidio colectivo, aunque no la formulen verbalmente.

$\mathrm{El}$ aislamiento funciona como detonante, pero ese mismo aislamiento planea desde el principio de la película. Las jóvenes apenas se relacionan con la gente y es tan sólo por el consejo del psiquiatra, tras el primer intento de suicidio de la pequeña, por lo que deciden llevar a alguien a la casa. Curiosamente, en lugar de una niña, es un joven el elegido para que la hija tenga más relaciones sociales, como sugiere el médico. Las hermanas no parecen tener amigas y viven aisladas en su mundo interior. De hecho, a pesar de ser sumamente atractivas, sólo Lux consigue un pretendiente, pretendiente que es invitado a ver la televisión en compañía de toda la familia, en una secuencia agobiante con la madre sentada en medio de los dos.

Y aunque parecería lógico que en algún momento escaparan de esa prisión, ya que tenían acceso al jardín, «todas vivían en la 
muerte, convirtiéndose en sombras», como expresa uno de los personajes que las observa. El aislamiento no sólo es físico sino interior y es llevado a sus últimas consecuencias con el suicidio de las cuatro hermanas. La última frase en off habla del mismo asunto.

No importa la edad que tuvieran, o que fueran chicas. Sólo que las amamos y que ellas no nos oyeron llamarlas y aún no nos oyen desde fuera de esas habitaciones donde ellas estarán solas para siempre y donde nunca encontraremos las piezas para hacerlas encajar.

2. En Lost in translation, guión original de Sofia Coppola, el aislamiento viene dado por la ciudad donde transcurre la película y la situación personal de los protagonistas. Bob y Charlotte son dos norteamericanos de visita en Tokio por distintos motivos. Él, actor en la crisis de los cincuenta, ha ido a hacer un spot de whisky y ella, de poco más de veinte años, a acompañar a su marido fotógrafo.

Desde el primer momento, Sofia nos cuenta que sus dos protagonistas están aislados de su rutina, separados de los suyos, aun cuando Charlotte ha llegado con su marido, puesto que la abandona para irse a trabajar.

La presentación de Bob le muestra a él solo en un coche; a Charlotte la muestra mirando sola por la ventana del dormitorio mientras su marido ronca en la cama.

Y enseguida sabemos más datos de la situación actual de los dos personajes. Él tiene una mujer que sólo se preocupa por la nueva moqueta o echarle en cara que ha olvidado el cumpleaños del hijo. El marido de ella la critica en las pocas ocasiones en que coinciden con frases del estilo «no todo el mundo ha ido a Yale». Es decir, son dos personas en un momento de crisis interior a las que el viaje les hará salir, aunque sea por unas horas, del aislamiento en 
que se encuentran. Y en cuanto queda establecida la situación de ambos, se da pie a una relación entre dos solitarios.

A pesar de ser Tokio una ciudad superpoblada, Coppola elige un hotel para aislar a su pareja del resto del mundo.

- Creo que el punto de partida fue Tokio. Solía viajar allí a menudo, he pasado largas temporadas en esta ciudad. Quería incluir en una película algunas de mis impresiones durante el tiempo que pasé allí: regresar a casa sola por la noche con las luces de neón, o escuchando música... [...] la primera vez que llegué a Japón, mi estancia en el hotel Park Hyatt que es un lugar de tranquilidad en medio de esta ciudad tan caótica.

Aunque en este caso, es a él a quién mantiene en el hotel mientras que a ella la saca a pasear sola por la ciudad, quizá para identificarla como el soplo de aire fresco que necesita el hombre en crisis de edad. Ella aparece como princesa que viene a rescatarle. Una princesa con sus propios problemas personales.

Vemos a Bob solo en el bar, en el gimnasio, viendo la televisión, jugando al golf, en la piscina... huyendo de quien le pide un autógrafo... A ella la vemos hablando por teléfono con su madre mientras le caen las lágrimas: «No sé con quién me he casado», y la madre cambiando de tema sin hacerle caso; visitando un templo, haciendo ikebana, en una sala de juegos recreativos... y luego encerrada en el hotel, en la bañera, escuchando una cinta de búsqueda del alma... Y ambos con insomnio, excusa que da pie a que se encuentren solos en el bar.

Charlotte es quien le invita a salir de noche con amigos de ella, $y$ tras un recorrido por distintos locales donde parecen disfrutar realmente el uno con el otro, acaban fumando en un pasillo solitario y por fin, de vuelta al hotel, los dos consiguen dormir. 
Al día siguiente, otra vez de noche, huyen de un local para aislarse de nuevo en el dormitorio a ver una película. En esta secuencia surge un diálogo que habla de las preocupaciones de la guionista, aunque es Charlotte quien las expresa.

-Estoy estancada. ¿Eso mejora?

—No, si... Se hace más fácil.

-No sé lo que quiero ser.

La misma sensación con distintas palabras dijo la propia autora en una de sus entrevistas relacionadas con la película:

-Creo que con veinte años uno se hace este tipo de preguntas. ¿Qué voy a hacer con mi vida? ¿Estoy tomando la decisión correcta?

En la misma secuencia, Charlotte habla de las cosas que ha probado, como escribir o hacer fotos, y de que sabe que es negada, pero él la anima a seguir escribiendo. Ahí solos, aislados del resto del mundo, su relación se convierte en el oasis de sus existencias.

Y de nuevo, un recorrido por la vida solitaria de ambos personajes hasta reunirlos en la despedida final, cuando los dos saben que sus vidas deben seguir por separado.

La última imagen de Bob es la misma del principio: él solo en el coche. La de ella, perdiéndose entre la multitud. De nuevo los dos aislados, aunque han aprendido a ser un poco más felices el uno con el otro.

3. María Antonieta vuelve a ser la adaptación cinematográfica de una novela, esta vez de Antonia Fraser, pero el tema es recurrente: una joven aislada por completo, no sólo de su familia sino 
también de su propio país. Sofia Coppola lo comenta en una entrevista con esta respuesta:

Siempre quise pensar en María Antonieta como en una joven americana que arriba al Viejo Continente. Una especie de Daisy Miller en la Francia del XVIII. Ella llega con toda la curiosidad natural de su edad para verse constreñida en algo más que un corsé.

María Antonieta es obligada en la frontera a despojarse de cualquier cosa que la una a su país, Austria. Incluso debe dejar a su perrito, lo que provoca una tristeza inmensa en la adolescente.

A partir de su llegada a la corte, aunque esté rodeada de multitud de personas relacionadas con el poder, ella siente que vive en una cárcel lujosa, con un marido que la abandona para ir de cacería y que no cumple en la cama.

En muchos momentos de la película vemos a María Antonieta sola: en el lecho nupcial, encerrada en un cuarto, paseando, aplaudiendo... Pero incluso rodeada de gente de su confianza, sabe que siempre será «la austríaca». Cuando su hermano llega a visitarla, la joven le hace una pregunta esperanzada:

- ¿Venís para llevarme a casa?

-No se puede raptar a la reina de Francia.

En la historia real, y que queda reflejada en la versión que Sofia Coppola adapta para su guión, la reina de Francia se hace construir un refugio para aislarse del ruido de la corte. Allí lleva una vida de campesina, tratando sin duda de encontrar un lugar que le pertenezca.

El único nexo de unión que tiene con su pasado es su madre, con la que mantiene una correspondencia abundante en la que es criticada por no hacer que su marido cumpla con el papel de 
esposo. María Antonieta es obligada a vivir en un país que no es el suyo y a partir de ahí, con tan sólo quince años es desposada con un extraño y abandonada en una corte que le es hostil. Coppola lo explica en una entrevista:

Desde el principio quise que se percibiera la absoluta ingenuidad y frescura del personaje, de esa joven llena de vida que llega a lo que se puede convertir en una tumba en vida.

Como en Las vírgenes suicidas, habla de una joven muerta en vida. De modo parecido se siente la protagonista de Lost in translation cuando dice que se siente estancada y no sabe qué hacer.

María Antonieta recurre a las compras, al juego, a las fiestas, tratando de romper el aislamiento al que le ha sometido el matrimonio concertado gracias a las alianzas políticas de la época. Pero lo único que consigue es que el pueblo se arme contra ella y la culpe de todas sus desgracias.

La joven reina, inclinada en el balcón frente a una muchedumbre que pide venganza, es el símbolo más clarificador de su soledad. Así lo cuenta Sofia en una entrevista:

Para mí, ése es el momento crucial en el que la niña princesa se transforma en mujer reina, o por supuesto en una mujer que es capaz de analizar lo que está sucediendo. Pero es demasiado tarde.

La joven ha vivido durante años aislada de lo que ocurría en el exterior del palacio, de manera que cuando el problema se hace insostenible, ya no tiene capacidad para controlarlo. Su inexperiencia, debida a su corta edad, ha sido la causa de su desdicha y eso me lleva a analizar otro de los temas recurrentes en las películas de Sofia Coppola: la juventud. 


\section{LA JUVENTUD FRENTE A LA MADUREZ}

En las tres películas escritas y dirigidas por Coppola, la edad de las protagonistas y el hecho de que sean mujeres tiene una importancia extrema. De hecho, los fotogramas iniciales nos hablan de ello. La primera imagen que aparece en pantalla en Las vírgenes suicidas es la protagonista, Lux, acabando de chupar el palo de un helado; en Lost in translation es un primer plano trasero de la braguita infantil semitransparente de Charlotte y en María Antonieta aparece la adolescente protagonista tumbada chupándose un dedo untado en pastel mientras le ponen un zapato. Tres imágenes realmente ingenuas de las que después serán las protagonistas de intensas historias. Como anécdota para demostrar que Sofia encara los trabajos desde su propia juventud, basta detenerse en un plano de María Antonieta, donde podemos ver unas deportivas junto a los zapatos de la reina, fruto seguramente de una chiquillada de la directora. Otra osadía fue emplear música moderna, y así se justificaba la propia Sofia:

Quise expresar un sentimiento adolescente a través de la música. María Antonieta y Luis tenían dieciocho y diecinueve años cuando fueron coronados. Eran jóvenes y algo traviesos y he utilizado una música que exuda aquel sentimiento de libertad y falta de responsabilidades.

En Las vírgenes suicidas, las cinco hermanas son menores de dieciocho años. Y la primera en suicidarse es justamente la menor, la de trece. Es interesante analizar el diálogo que mantiene el médico con ella tras el intento de suicidio fallido.

-Eres muy joven para saber lo mala que es la vida.

-Usted nunca ha sido una chica de trece años. 
En este diálogo el médico nos cuenta que la vida es mala, aunque uno no debería saberlo a tan corta edad. Los que parecen saberlo en las tres películas son los adultos.

En Lost in translation, Bob cuenta lo que significa la vida después de veinticinco años de casado. Cuando Charlotte le pregunta qué hace en el hotel, él responde:

-Descansar de mi mujer, olvidar el cumpleaños de mi hijo y ganar dos millones promocionando un whisky.

Y en María Antonieta, la madre se lo dice claramente en una de sus cartas:

Recordad que representáis el futuro y no hay nada seguro sobre vuestra posición ahí si el acto físico definitivo para la alianza franco-austríaca no se realiza.

La juventud frente a la madurez, de eso hablan los tres guiones de Sofia Coppola; de las jóvenes sobre todo, ya que muestra personajes femeninos en los tres casos, chicas que tienen todo el futuro por delante y no saben qué hacer con él, o simplemente no les gusta lo que está por llegar. Así lo explican los adolescentes de Las vírgenes suicidas:

-Supimos que las chicas son mujeres disfrazadas, que entienden el amor y la muerte, lo saben todo sobre nosotros. Nosotros no sabemos nada de ellas.

En esta película la madre tiene miedo de la juventud de sus hijas. No las deja salir si no es con el padre de carabina, o ella misma vigilando que nadie se salte las normas. El protagonista de la segunda está en crisis de edad y no sabe cómo manejar los pocos 
años de esa joven mujer que tanto le atrae. De hecho, cuando Bob tiene una aventura de una noche con una mujer adulta, la misma Charlotte le justifica:

—Ella es más de tu edad.

Y en la tercera, la juventud es la causante de todas las desgracias de María Antonieta. Quizá porque Sofia Coppola empezó a trabajar desde muy joven, y muy especialmente en su caso, por ser hija de quien es, nos encontramos con otro de los temas coincidentes en los tres guiones: los hijos. En sus tres películas este elemento funciona como conflicto. Si ser hijo es difícil, lo es aún más cuando se tiene la figura de un padre poderoso y triunfador. La opinión de la guionista sobre el tema queda reflejada en sus personajes y diálogos, a veces de manera brutal.

\section{LOS HIJOS}

Sin lugar a dudas, las hijas son el componente indispensable de Las vírgenes suicidas. Las hijas ponen en marcha la historia y son las protagonistas de la tragedia. Pero estos personajes no funcionarían si no tuvieran enfrente a la madre dominadora, una mujer que es incapaz de entender lo ocurrido tras el suicidio de sus cinco hijas, como expresa en la últimas frases de la película:

-Nunca les faltó amor. Nunca les faltó amor.

El amor maternal queda dibujado como ahogo de las jóvenes, con una madre castradora hasta el punto de encerrarlas sin permitirles ir a clase. Una madre que les confecciona sacos para que asis- 
tan al baile, que interroga a los chicos que vienen a buscarlas, que golpea a la hija díscola y la obliga a deshacerse de sus discos favoritos... una madre con unas reglas tan estrictas que sus hijas sólo saben romper quitándose la vida.

En Lost in translation, Sofia Coppola escribe una de las frases más demoledoras que se hayan escuchado sobre los hijos, y la pone en boca de su protagonista, Bob:

- Todo se complica mucho cuando tienes hijos. El más aterrador es el primero. Tu vida tal como la conoces se va... para no volver.

Interrogada sobre esta frase, la misma autora declara:

Recuerdo a dos amigos algo más mayores que yo que me dijeron lo mismo, algo que me sorprendió mucho por lo poco habitual, y sólo podía atraer la atención de una joven que se cuestionaba ciertas cosas sobre su vida.

Bob olvida el cumpleaños de su hijo, habla sobre las consecuencias de la paternidad y de lo encantadores que se vuelven esos hijos que tanto miedo te han dado al nacer. Y no olvidemos que la diferencia de edad entre él y Charlotte es tan grande como para poder ser padre e hija. Si exceptuamos el último beso, se relacionan con la misma ternura que un padre lo haría con su pequeña: la besa en la mejilla, la lleva en brazos cuando se duerme, se agarran de la mano, se acuestan uno junto al otro sin tocarse...

María Antonieta es la historia de una hija convertida en reina por deseo de su madre, de nuevo una madre dominante que critica a su hija en la distancia, sin preocuparse por conocer sus sentimientos. En una de las cartas que le envía escuchamos palabras tan duras como éstas: 
Queridísima Antonieta. Está claro que los problemas en vuestro nuevo hogar se derivan de vuestra incapacidad para inspirar pasión sexual a vuestro marido. No hay razón para que una joven con todos vuestros encantos se encuentre en esta situación.

Y la hija obedece sin rechistar, aunque no logra el objetivo de conquistar a su marido en la cama hasta muchos años después. Más adelante, la madre vuelve a la carga en otra de sus misivas para hablar de nuevo sobre el hijo que no llega.

Todo depende de la esposa, si es cariñosa y dispuesta. No me canso de repetiros lo importante que es que empleéis vuestro encanto y paciencia, nunca el mal humor para remediar esta lamentable situación. Recordad que nada de lo que tenéis está asegurado hasta que llegue un heredero.

El futuro de María Antonieta depende del hecho de que sea madre y dé un heredero a la corona de Francia. La maternidad por encima del amor, de los deseos, del hecho de ser persona. Y coincidiendo en las tres películas, unas madres que asfixian a sus hijas con sus demandas, o ignorando sus problemas como en el caso de Lost in translation.

Sofia Coppola, mujer y cineasta valiente, que ha encontrado un camino personal donde desarrollar su talento tantas veces cuestionado en su faceta de actriz, habla también de lo femenino en sus guiones, mostrando unas mujeres sensuales y fuertes a partes iguales. Sus protagonistas, a pesar de su corta edad, son las que toman las decisiones, ya sea para bien o para mal como en Las vírgenes suicidas, cuando ellas se quitan la vida, o Charlotte pidiéndole a Bob que se quede con ella en Lost in translation, o María Antonieta 
eligiendo quedarse junto a su marido en plena revolución. De la misma manera, en el terreno sexual son sus mujeres quienes toman la iniciativa en los tres casos. El personaje de Lux es quien seduce al joven, le acaricia por primera vez, le besa por sorpresa, hace el amor con desconocidos... Charlotte es quien se acerca por la noche a la barra para hablar con el recien llegado; es ella quien le invita a salir, quien le dice que se quede, que va a echarle de menos... Y María Antonieta se esfuerza por ser deseada en la cama, se perfuma, toca a su marido, le mira con pasión... y por fin se queda a su lado en el peor momento.

Esta elección de centrar las historias en personajes femeninos no significa, en cambio, que los hombres queden relegados a un segundo plano. Son hombres con personalidades definidas, magníficos coprotagonistas de las historias de ellas. Incluso en el caso de Lost in translation, que Coppola imaginó a partir de un hombre en la crisis de los cincuenta, es Charlotte quien pone en marcha la peripecia. Si no fuera por su decisión de acercarse a él, no avanzaríamos en la relación de esta singular pareja.

Tan sólo tres largometrajes han situado a Sofia Coppola entre los cineastas más prestigiosos de los últimos años. El Oscar al mejor guión conseguido por Lost in translation y haber sido la primera directora americana nominada al Oscar en esta categoría, así lo confirman. En una industria tan ardua como la cinematográfica, Sofia Coppola parece haber encontrado la vía para desarrollar una personalidad que vuela por encima de su apellido. 